\title{
Chapter 10 \\ Railways and Wildlife: A Case Study \\ of Train-Elephant Collisions in Northern \\ West Bengal, India
}

\author{
Mukti Roy and Raman Sukumar
}

\begin{abstract}
The extensive network of the Indian Railways cuts through several forested landscapes, resulting in collisions of trains with a variety of wildlife species, including the largest land mammal-the elephant. In India, railway lines cross elephant habitats in several states, with accidents that resulted in more than 200 elephant deaths between 1987 and 2015. As the 161-km Siliguri-Alipurduar track in the northern West Bengal state witnesses train-elephant collisions frequently, we developed a case study there with the objectives of mapping locations of collisions and generating a susceptibility map showing locations prone to accidents. We mapped elephant crossing points and movement paths along this railway track, as well as accident locations. Between 1974 and 2015, collisions occurred throughout the line, although there were several hotspots where elephant deaths were concentrated. A disproportionate number of accidents occurred during the night. Crop raiding in villages and train elephant accidents seem to be closely related, probably due to an increased frequency of elephant movement near or across this railway track during the cultivation season. Male elephants were much more prone to accidents, possibly because of behavioural characteristics that make them cross railway tracks more frequently. To reduce the frequency of accidents in this region, we recommend reducing the speed of trains, limiting the operation of trains during at night, provisioning overpasses and underpasses, using communications technology, realigning a portion of the track, and fencing the track except for corridor areas.
\end{abstract}

Keywords Train elephant accidents - Elephant deaths - Crop raiding - Accident susceptibility map · Northern West Bengal

\author{
M. Roy $(\bowtie)$ \\ Asian Nature Conservation Foundation, c/o Centre for Ecological Sciences, \\ Indian Institute of Science, Bangalore 560012, Karnataka, India \\ e-mail: muktiroy@ rediffmail.com \\ R. Sukumar \\ Centre for Ecological Sciences, Indian Institute of Science, \\ Bangalore 560012, Karnataka, India \\ e-mail: rsuku@ces.iisc.ernet.in \\ (C) The Author(s) 2017 \\ L. Borda-de-Água et al. (eds.), Railway Ecology, \\ DOI 10.1007/978-3-319-57496-7_10
}




\section{Introduction}

Many animals range widely across landscapes in the quest to meet their daily, seasonal and annual biological needs of food, water, shelter and mates (Caughley and Sinclair 1994). Habitat connectivity within a landscape helps dispersal and re-colonization, thus maintaining regional metapopulations and minimizing risks of inbreeding within populations (Newmark 1987; Wilcove et al. 1998). Historically, the spread of agriculture probably contributed the most to loss and fragmentation of their natural habitat. In an increasingly industrialized world, however, transport networks (railways, roads, and waterways) or so-called "linear infrastructures," restrict the movement of wildlife populations by fragmenting their habitat, increasing edge effects, constricting ecological corridors, blocking animal movement, and increasing the risk of mortality due to direct collisions with motorized vehicles (Forman and Deblinger 2000; Trombulak and Frissell 2000; Inell et al. 2003; Van der Ree et al. 2011). These processes hinder the persistence of species in human-dominated landscapes because small and isolated populations are more vulnerable to extinction from stochastic demographic processes and loss of genetic variation (Soule and Wilcox 1980).

Roads are perhaps the most widespread and pervasive form of "linear infrastructure" that have greatly impacted wildlife populations in the more developed parts of the world through habitat loss, restriction of animal movements, alteration of animal behaviour, and directly injuring or killing very large numbers of animals in collisions with vehicles (Trombulak and Frissell 2000; Seiler and Helldin 2015). A variety of animals are involved in road-kills, from large-bodied ones such as moose to smaller creatures such as frogs (Fahrig et al. 1995; Formann et al. 2003; Dorans et al. 2012). One estimate of road-kills suggested that 1,000,000 vertebrates were killed in the USA every day (Lalo 1987), while Conover et al. (1995) estimated that the number of deer-vehicle collisions in the USA exceeds 1,000,000 annually, causing approximately 29,000 human injuries and 200 fatalities, apart from animal fatalities. Given the magnitude of animal road-kills and the occurrence of human fatalities, there has been much attention paid to mitigating wildlife road kills through the appropriate design of roadways in many developed countries (Clarke et al. 1998; Inell et al. 2003). In contrast, only limited attention has been paid to wildlife-train collisions, although this has also been happening on significant scales in many countries. For instance, 200 moose train collisions were estimated in the province of British Columbia, Canada, during 1988-1990 (Child et al. 1991), with 266 collisions in a $92 \mathrm{~km}$ section of railways in Norway during 1980 1988 (Andersen et al. 1991), and between 9 and 725 collisions annually in Alaska (Modafferi 1991). Similarly, 69 roe deer train collisions in the Czech Republic were reported during 2009 (Kusta et al. 2014). Therefore, there is an urgent need for more information on train-wildlife collisions, and how these may be mitigated.

India is one of the countries with serious problems of train-wildlife collisions. This is because the Indian Railways (IR) is one of the world's largest railway networks, comprising $115,000 \mathrm{~km}$ of tracks over a route of about $65,000 \mathrm{~km}$ and 
7500 stations (Indian Railways 2014). In 2015-2016, IR transported more than 22,000,000 passengers and 3,000,000 tons of freight daily (Indian Railways 2015). Furthermore, the Indian Railway network cuts across various forested landscapes, and its impact on wildlife and their habitats has been a matter of increasing concern, although there are few studies on the subject. Direct as well as indirect impacts of the railways have exacerbated over the years with the expansion of the rail network, gauge conversion, and increases in frequency and speed of trains to meet the needs of a modernizing society and an increasing population. A number of larger mammalian species including gaur (Bos gaurus), rhinoceros (Rhinoceros unicornis), sambar deer (Rusa unicolor), nilgai (Boselaphus tragocamelus), sloth bear (Melursus ursinus), leopard (Panthera pardus), lion (Pathera leo) and tiger (Panthera tigris) have been killed in collision with trains (MOEF 2010; Raman 2011; Dasgupta and Ghosh 2015).

Ironically, the mascot of the Indian Railways, the Asian elephant (Elephas maximus), has itself been a frequent victim of train collisions (Singh et al. 2001; Sarma et al. 2006; Roy et al. 2009), which is a cause of conservation and safety concerns. Railway tracks pass through elephant habitat in several Indian states, including Assam, West Bengal, Uttarakhand, Jharkhand, Odisha, Kerala and Tamil Nadu, with accidents resulting in more than 200 elephant deaths between 1987 and 2015. Train-elephant collisions have been common along railway lines such as the Siliguri-Alipurduar line in northern West Bengal (Roy et al. 2009), GuwahatiLumding line in Assam and Meghalaya (Sarma et al. 2006), Haridwar-Dehradun line in Uttarakhand (Singh et al. 2001), and Coimbatore-Thrissur line in Tamil Nadu and Kerala (Jha et al. 2014). Railway-elephant collisions have also occurred along the Delhi-Howrah line within Jharkhand state (see news report, The Times of India, 02.08.2013), and the Kharagpur-Adra railway line in southern West Bengal (West Bengal Forest Department 2013). To give an idea of the numbers of accidents involving elephants along these tracks, 18 elephant deaths were recorded at Rajaji National Park, Uttarkhand, between 1987 and 2001 (Singh et al. 2001), 35 deaths in Assam from 1987 to 2006 (Sarma et al.2006), 16 in Odisha (Palai et al. 2013) and 13 elephant deaths in Tamil Nadu between 2002 and 2013 (Jha et al. 2014). However, the Siliguri Alipurduar track in northern West Bengal has witnessed the highest numbers of elephant deaths in train collisions; while 27 deaths were recorded between 1974 and 2002, the figure rose to 65 between 2004 and 2015 (Roy et al. 2009; Dasgupta and Ghosh 2015; Roy and Sukumar 2016).

As northern West Bengal is a "hotspot" of train-elephant collisions, we carried out a case study of this phenomenon with the following objectives: (1) mapping the locations of collisions and generating a susceptibility map showing locations prone to accidents; (2) understanding patterns in accidents involving elephants; (3) mapping elephant crossing points and their movement paths along the railway track; and (4) providing suggestions for reducing the incidence of accidents. 


\section{Methods}

\section{Study Area}

This case study was carried out along the 161-km long railway line between the Siliguri Junction (latitude $26.70758^{\circ} \mathrm{N}$, longitude $88.42761^{\circ} \mathrm{E}$ ) and the Alipurduar Junction (latitude $26.49099^{\circ} \mathrm{N}$, longitude $89.52644^{\circ} \mathrm{E}$ ) in northern West Bengal state, India. The Eastern Bengal Railway (EBR) was one of the pioneer railway companies in the former Bengal and Assam provinces of British India from 1857 to 1942. The Siliguri Alipurduar track was built during 1910-1911, using non-standard meter gauge (MG). Major tracts of tropical moist forests dominated by sal (Shorea robusta) were cleared to establish the railway line and to expand tea (Camellia sinensis) plantations. Other forests were also cut to make way for establishing agricultural land and to provide the wood to make the railway sleepers. These forests supported a large elephant population from historical times (GoWB 1957) and even supplied elephants for use in armies of Sultanate and Mughal rulers, and later in logging operations by the British (Sukumar 2011). Post-independence, the Eastern Bengal Railway operating in Assam and northern Bengal came under the jurisdiction of the North-East Frontier Railways.

This railway line passes through an elephant range that is part of the Eastern Himalayan biodiversity hotspot and the Eastern Dooars Elephant Reserve (Roy et al. 2009). The line cuts through a mixture of forests, tea gardens, towns, crop lands, human settlements, army establishments, streams, rivers, and elephant corridors within the districts of Darjeeling, Jalpaiguri, and Alipurduar. Established in the early nineteenth century primarily to serve the tea industry (Ray 2002) and the extraction of timber from this region, the line initially had a "meter-gauge track" distance between two rails $=1000 \mathrm{~mm} / 3 \mathrm{ft} 33 / 8 \mathrm{in}$.); at that time, only a few trains used the line and did so at maximum speeds of $60 \mathrm{kph}(37 \mathrm{mph})$. However, given the increasing demand to improve connectivity between the states of north-eastern India and the rest of the country, this railway line was converted from meter-gauge to broad-gauge (distance between two rails $1676 \mathrm{~mm}$ or 5' 6") in 2003. Broad-gauge lines can carry heavier loads (including more people) and withstand higher train speeds; consequently, the number of freight and passenger trains on the track has almost doubled. The speed of trains has also increased to more than $100 \mathrm{kph}(62 \mathrm{mph})$. Over $74 \mathrm{~km}(46 \mathrm{mi})$ of this line run through forested areas, including several protected areas (Mahananda Wildlife Sanctuary, Gorumara National Park, Chapramari Wildlife Sanctuary, Jaldapara National Park and Buxa Tiger Reserve), as well as through more than 40 tea gardens, 4 army establishments, and agricultural land (mainly paddy and maize, cultivated seasonally). 


\section{Data Collection}

We collected data on elephant casualties due to collisions with trains between 1974 and 2015, using records maintained by the Government of West Bengal (2012), the Alipurduar Divisional Railway Manager's office, several offices of the West Bengal Forest Department, tea association offices, scientific reports and publications (Roy et al. 2009; Dasgupta and Ghosh 2015), and newspaper reports. These records include date, time, location, number of animals injured or killed, and the gender and age groups of these animals. We also collected first-hand information on some of the more recent accidents during our field research on elephant ecology in this region.

To estimate the distribution and relative abundance of elephants, we conducted surveys along this railway track during three seasons in 2015: non-crop (Jan-Mar), maize cultivation/harvest (Apr-Jul), and paddy cultivation/harvest (Aug-Dec). The survey was done along a $150 \mathrm{~km}$ stretch of the $161-\mathrm{km}$ railway track, excluding a part of the Siliguri Junction-Gulma station and Rajabhatkhawa station-Alipurduar junction, as these portions fall within human habitation areas with no elephant presence. The surveys were conducted along the track on foot by a team consisting of one researcher and two assistants, aiming to detect elephant signs (dung, tracks, footprints, feeding signs), as well as direct sightings, on both sides of the track, up to a distance of $10 \mathrm{~m}$. Every sign was counted separately and thus footprints, dung, and tracks at a particular location were counted as three separate pieces of evidence, as in general it was not possible to determine whether these signs, most of which were old, came from the same elephant or different ones. The paddy season survey also included the mapping of elephant corridors, which mostly pass through tea gardens in this region. All the evidence of elephant evidence that we detected were GPS-referenced and plotted on Arc GIS 10.3.1. (ESRI 2014). The non-crop season survey took 33 days, the maize season survey 22 days, and the paddy season survey 41 days to complete.

\section{Data Analysis}

Using data on the spatial distribution of elephant signs (dung, footprints, track signs, feeding signs), we generated a "susceptibility map" to estimate the locations along the railway track where accidents were more likely to occur due to the concentration of elephant activity. This map was computed using the point density tool of Arc GIS 10.3.1 software, and the GPS locations of elephant signs. The point density tool calculates the density of point features around a given neighborhood of each raster cell by dividing the number of points that fall in the neighborhood by the area of the neighborhood. In our computations, we used an output cell size of $0.001375 \mathrm{~km}^{2}$ and search radius of $0.11458 \mathrm{~km}$, based on values provided automatically by the GIS software. We also generated a "kernel density map" in ARC GIS 10.3.1, taking into account all indirect evidence of elephants (dung, 
Table 10.1 Number of elephant signs (see text for list) recorded in different sectors along the railway track in northern West Bengal (Siliguri Junction-Alipurduar Junction; see Fig. 10.7 for locations of stations)

\begin{tabular}{l|l|l|l}
\hline From (sector station) & To (sector station) & Distance $(\mathrm{km})$ & Signs $/ \mathrm{km}$ \\
\hline Siliguri Junction & Bagrakote & 33 & 7.7 \\
\hline Bagrakote & Chalsa & 22 & 0.8 \\
\hline Chalsa & Dalgaon & 46 & 4.4 \\
\hline Dalgaon & Hasimara & 25 & 3.5 \\
\hline Hasimara & Alipurduar Junction & 35 & 5.9 \\
\hline
\end{tabular}

footprints, track signs, feeding signs) found along the railway track. For point data, the kernel density is a nonparametric method of estimating the probability density function of a random variable that calculates the density of point features around each output raster cell with a smoothly curved surface fitted over each point. Estimates were based on the Silverman (1986) quartic kernel function. The output cell size and search radius were taken as for the "susceptibility map."

To understand temporal patterns of elephant casualties, we used nonparametric statistical tests to determine whether the number of accidents changed between before gauge conversion (1974-2002) and after it (2004-2015). We also evaluated temporal patterns in accidents according to season of the year and time of day for records after gauge conversion. For analysis, accidents were aggregated within the three seasons described above, and in two daily periods, i.e., day (06:00-18:00) vs night (18:00-06:00).

\section{Results}

\section{Elephant Distribution}

During the three seasonal field surveys for elephants, we found 589 indirect signs during the dry season, 599 signs during the maize cultivation/harvest season, and 1,124 signs during the paddy cultivation/harvest season along the $150 \mathrm{~km}$ stretch of the railway track. Overall, most signs were found in the Siliguri-Bagarkote (Mahananda-Monpong stretch) sector in the western region $(8.0 \mathrm{signs} / \mathrm{km})$, followed by the Hasimara-Alipurduar (Buxa Tiger Reserve West) sector in the eastern region (6.0 signs/km) (Table 10.1).

\section{Elephant Fatalities}

Eighty-nine (89) elephant deaths were reported from 61 accidents over a 41-year period (1974-2015), with a marked increase over time (Fig. 10.1) in the number of 


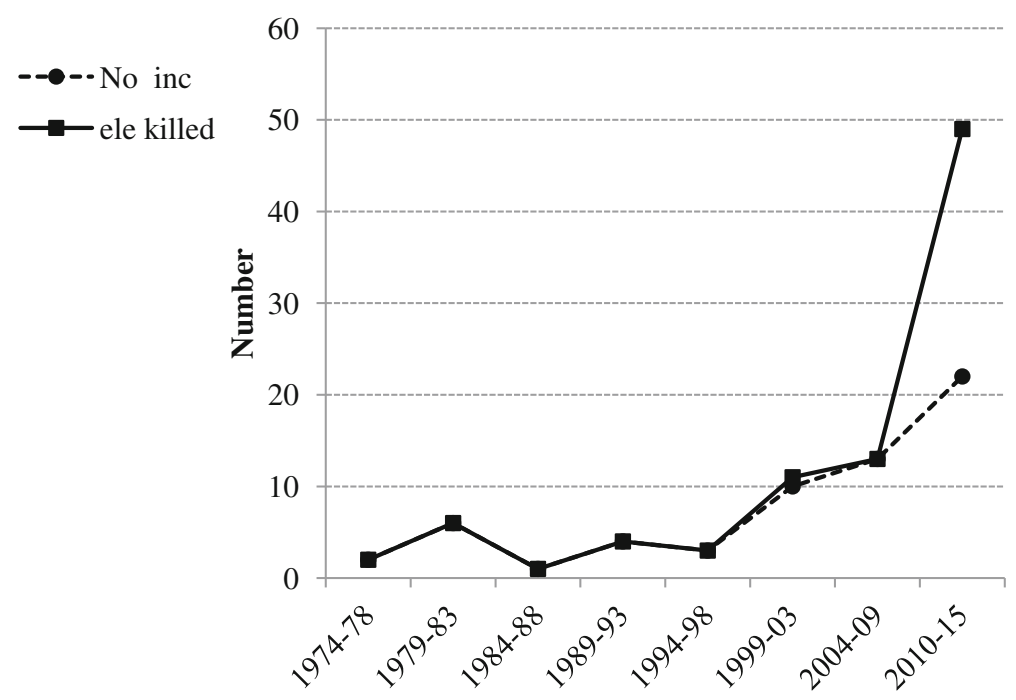

Fig. 10.1 Temporal variation between 1974 and 2015 in the number of train-elephant collision accidents (No inc) and in the number of elephants killed (ele killed) per 5-year period, in the Siliguri-Alipurduar railway, northern West Bengal, India

accidents (Pearson's $\mathrm{r}=0.82, P<0.05$ ) and the number of elephants killed per year $(\mathrm{r}=0.96, P<0.0001)$. Between 1974 and 2002, when meter gauge (MG) was in operation, 27 elephants died in 26 accidents, corresponding to 0.90 accidents/year \pm 1.11 (SD) and $0.93 \pm 1.19$ (SD) elephants/accident. In the 12 years (2004-2015) after conversion to broad gauge (BG), these figures jumped to 62 fatalities in 35 accidents, corresponding to 2.92 accidents/year \pm 1.98 (SD) and $5.17 \pm 5.89$ (SD) elephants/accident. There were statistically significant differences between the time periods before and after gauge conversion, for both the annual number of accidents (Mann-Whitney $U=283.5, \mathrm{Z}=-3.13, P<0.001$ ) and the annual number of animals killed (Mann-Whitney $U=290.5, \mathrm{Z}=-3.33$, $P<0.001)$.

We also analyzed data in more detail for accidents occurring from 2004 to 2015 (after gauge conversion). Females accounted for most of the animals killed in train collisions, while adults ( $>15$ years) constituted nearly $60 \%$ of all mortality recorded (Table 10.2). Also noteworthy is the relatively high mortality of calves (Table 10.2). Comparing these figures with available data on the age structure of elephant populations in northern West Bengal (Sukumar et al. 2003), we found that adult elephant males were killed far more frequently (31\% or more than 2.5 -fold) than what would have been expected from their representation in the population (13\%; Table 10.2). A proportions test also showed that adult males $(\mathrm{Z}=3.831$, $P<0.001)$, and calves $(\mathrm{Z}=2.136, P=0.037)$ were involved to a significantly greater extent in train accidents $(\mathrm{n}=62)$ than their representation in the population $(n=650)$. 
Table 10.2 Age structure of the elephant population in northern West Bengal (based on Sukumar et al. 2003) and those killed in train elephant collisions in the Siliguri-Alipurduar railway between 2004 and 2015

\begin{tabular}{l|l|l|l|l}
\hline Age class & $\begin{array}{l}\text { \% Females } \\
\text { in population }\end{array}$ & $\begin{array}{l}\text { \% Females killed in } \\
\text { train accidents }\end{array}$ & $\begin{array}{l}\text { \% Males in } \\
\text { population }\end{array}$ & $\begin{array}{l}\text { \% Males killed } \\
\text { in train accidents }\end{array}$ \\
\hline Adult & 33.3 & 29.0 & 12.9 & 30.6 \\
\hline Sub-adult & 11.1 & 11.3 & 12.3 & 8.1 \\
\hline Juvenile & 13.5 & 4.8 & 8.8 & 0.0 \\
\hline Calves & 4.1 & 8.1 & 4.1 & 8.1 \\
\hline Total & 62.0 & 53.2 & 38.0 & 46.8 \\
\hline
\end{tabular}

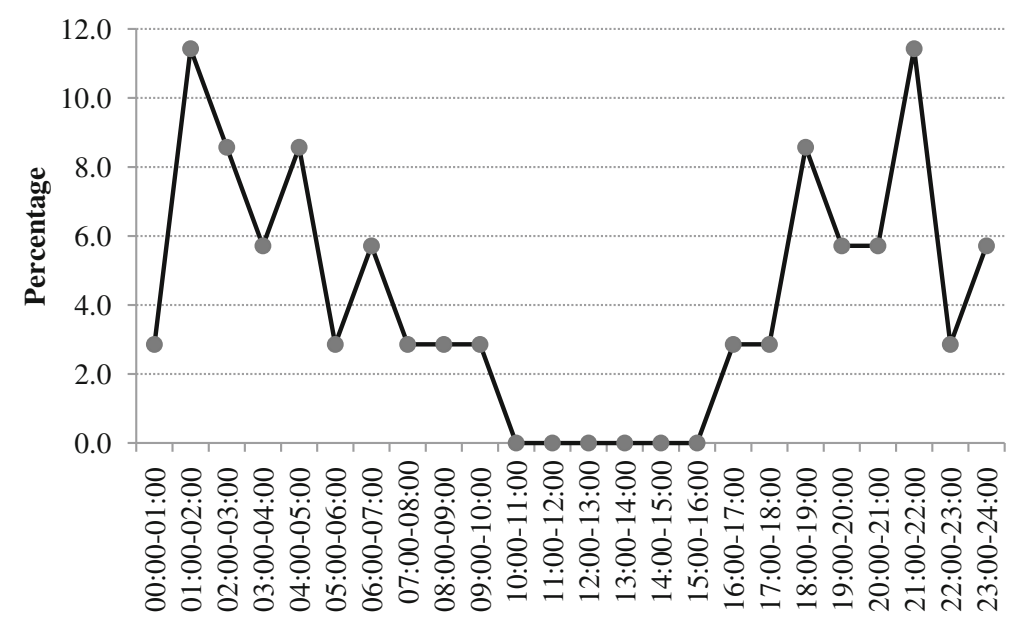

Fig. 10.2 Temporal distribution of train-elephant collisions during the daily cycle from 2004 until 2015 (after broad gauge conversion), in the Siliguri-Alipurduar railway, northern West Bengal, India

Also in 2004-2015, we found that the occurrence of elephant-train collisions varied markedly during the daily cycle. In fact, most accidents occurred between midnight and 6:00 and 16:00-24:00, with peaks at 01:00-2:00 and 22:00-23:00 (Fig. 10.2). More accidents occurred during the night (80\%), and this was significantly higher than during the day $(\mathrm{Z}=3.198, P=0.002)$. There were also significant seasonal patterns in the number of accidents (Kruskal-Wallis $H=12.69$, $P=0.05$ ) and the number of elephant deaths (Kruskal-Wallis $H=39.70$, $P=0.05$ ), with both occurring most frequently during the paddy cultivation season, followed by maize and non-crop seasons (Fig. 10.3). The association of accidents with elephants with the crop cultivation seasons is further emphasized by the strong correlation between the monthly proportion of elephants killed and the frequency of crop raiding by elephants in villages (all seasons: $\mathrm{r}=0.38, P=0.11$; maize season: $\mathrm{r}=0.81, P=0.025$; paddy season: $\mathrm{r}=-0.037, P=0.47)$. In fact, there were 


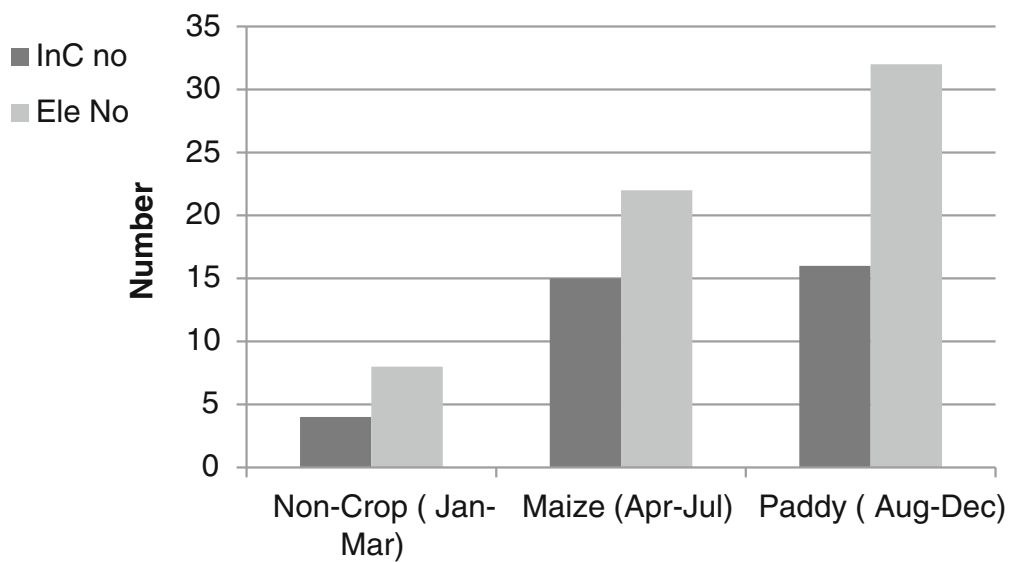

Fig. 10.3 Variation in relation to season in the number of accidents ( $\mathrm{InC}$ no) and number of elephants killed (ele no) in collisions with trains during 2004-2015 (after broad gauge conversion) in the Siliguri-Alipurduar railway, northern West Bengal, India

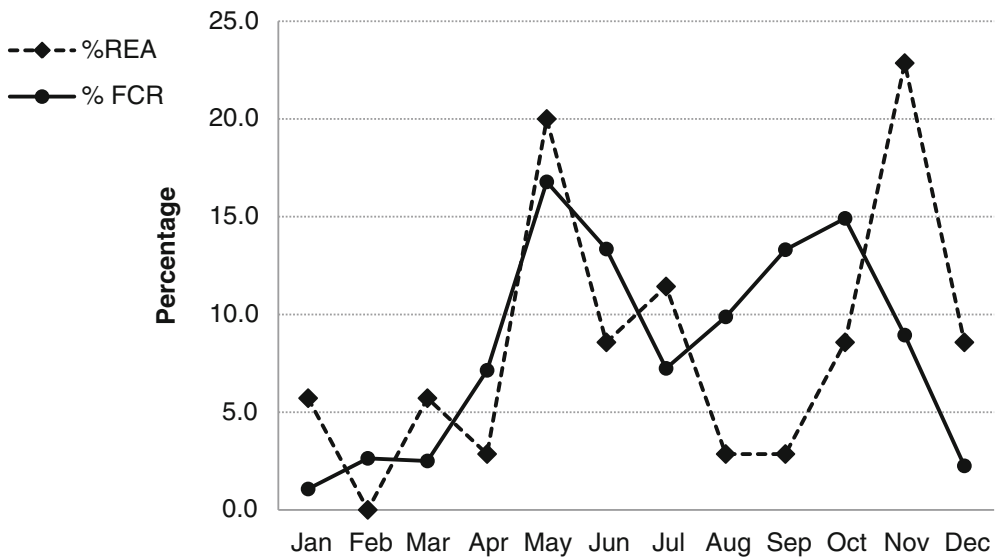

Fig. 10.4 Monthly variation of railway elephant accidents (REA) between 2004 and 2015 (after broad gauge conversion), in the Siliguri-Alipurduar railway, and in the frequency of crop raiding (FCR) by elephants in villages. Data on crop raiding are based on Sukumar et al. (2003) and Roy (2010)

simultaneous peaks in elephant mortality and crop raiding during the year, corresponding to the maize (May-June) and paddy-harvesting season (Oct-Dec) (Fig. 10.4). 


\section{Spatial Distribution of Collision Risk}

There was a strong spatial variation in the number of accidents both before and after gauge conversion (Fig. 10.5), with many accidents occurring in the same areas and none in others. The concentrations of accidents matched some areas with high elephant activity as estimated from the densities of elephant signs (Fig. 10.6), but there were also areas with large densities of elephant signs but with no or just a few accidents. However, when we divided the entire railway line surveyed into segments of $2 \mathrm{~km}$ each $(\mathrm{n}=76)$ and plotted the elephant signs found (dung, tracks, foot prints, feeding signs) in each segment with the number of accidents that occurred, we found a strong correlation (Spearman's rank correlation $r=0.80$, $P \leq 0.001)$.

During 2004-2015, after gauge conversion, the Buxa Tiger Reserve West Division region recorded the highest number $(29 \%)$ of the accidents that took place $(n=35)$, followed by the Mahananda Wildlife Sanctuary $(26 \%)$, the Jalpaiguri Forest Division (17\%), the Jaldapara Wildlife Division (14\%), the Kalimpong Forest Division (9\%), and the Gorumara Wildlife Division (6\%). When we consider the number of elephants killed $(n=62)$, the highest figures were observed in Jalpaiguri (31\%), followed by the Buxa Tiger Reserve West $(26 \%)$, Gorumara Wildlife (16\%), Mahananda Wildlife Sanctuary (15\%), Jaldapara Wildlife Division $(8 \%)$, and Kalimpong Division (5\%). More elephant groups were involved in accidents in Gorumara and Jalpaiguri resulting in multiple fatalities per accident.

\section{Discussion}

Our study describes the spatial and temporal mortality patterns of elephants due to collisions with trains along a $150-\mathrm{km}$ stretch of the $161-\mathrm{km}$ railway line between the Siliguri and Alipurduar Junctions. Collisions occurred throughout the study period (1974-2015), but they greatly increased after 2004, when a new schedule of trains began operating, after the line was converted from meter gauge to broad gauge. Most collisions occurred during the night, and adult male elephants and calves appeared particularly susceptible to this type of mortality. There was an uneven distribution of accidents during the annual cycle, with peaks in May-June and September-October, during the crop cultivation seasons of maize and paddy rice, respectively. The spatial distribution of accidents was also uneven, occurring mostly in a few well-defined hotspots. Overall, our study provides useful information to mitigate elephant-train accidents in the Siliguri-Alipurduar railway, and elsewhere in India.

One reason for the increase that was seen in the frequency of accidents was probably the increase in the number of circulating trains, from about 10 trains/day during the pre-conversion period, to estimates of between 17 (Ghosh 2001) and 2226/day (Das 2013) during the post-conversion period, thereby increasing the 

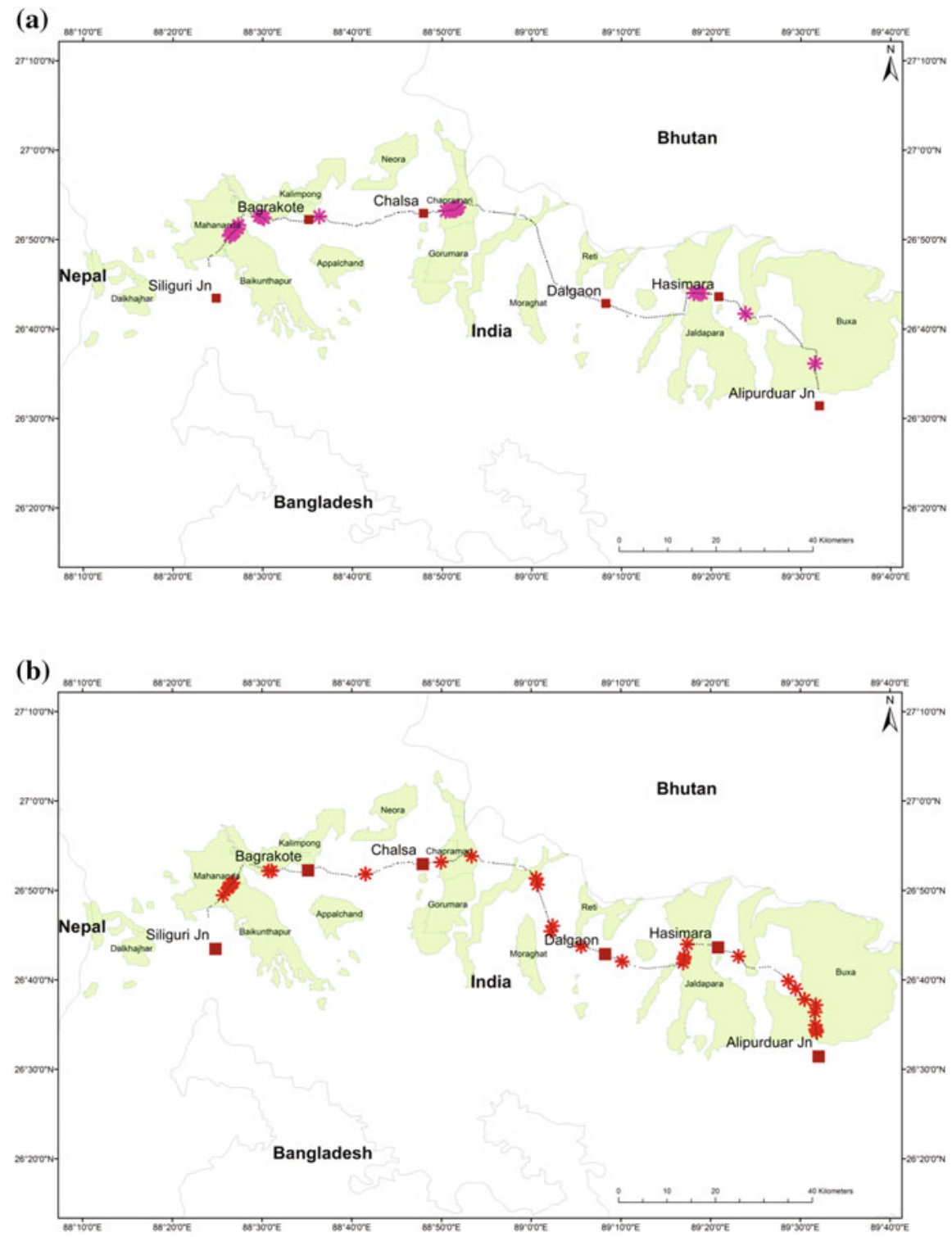

Fig. 10.5 Locations of elephant-train accidents in northern West Bengal between 1974 and 2002 (upper panel, a) when meter gauge was in operation (pink stars indicate locations where accidents occurred), and during 2004-2015 (lower panel, b), after broad gauge conversion (red stars indicate locations where accidents occurred)

chances of an elephant encountering a train when crossing the railway. Also, broad gauge allows trains to reach higher velocities, making it harder for elephants to avoid a moving train. In fact, after gauge conversion, the maximum speed of trains 


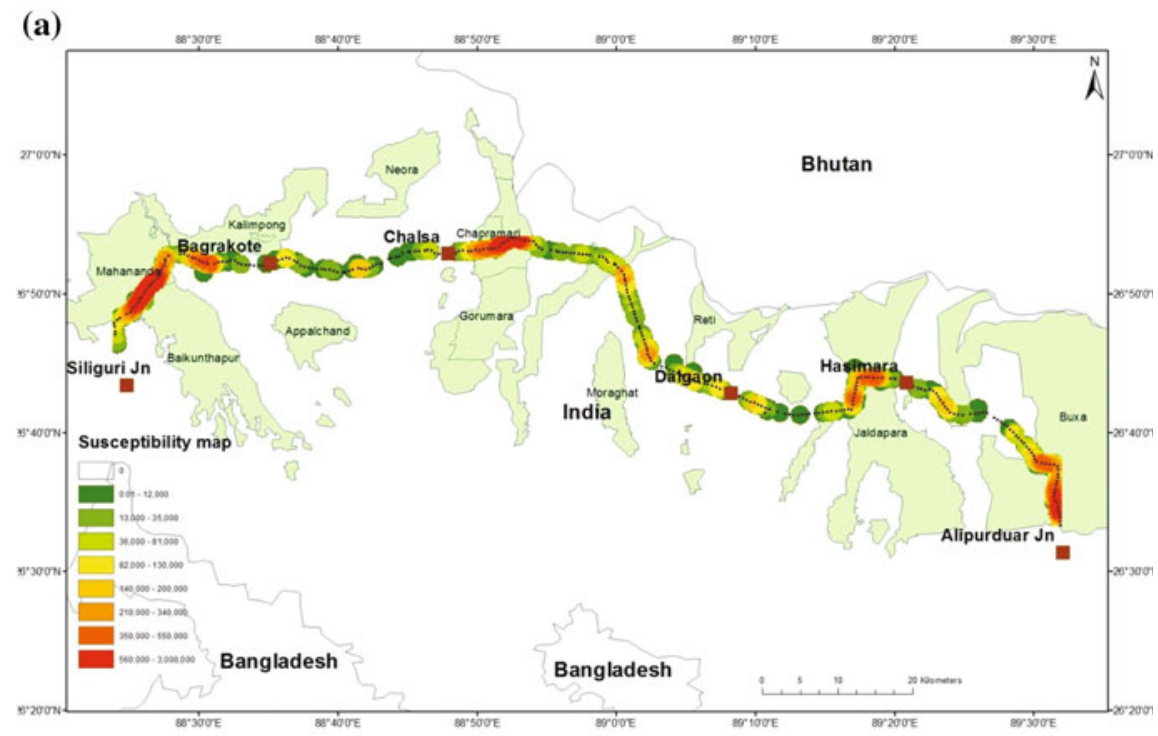

(b)

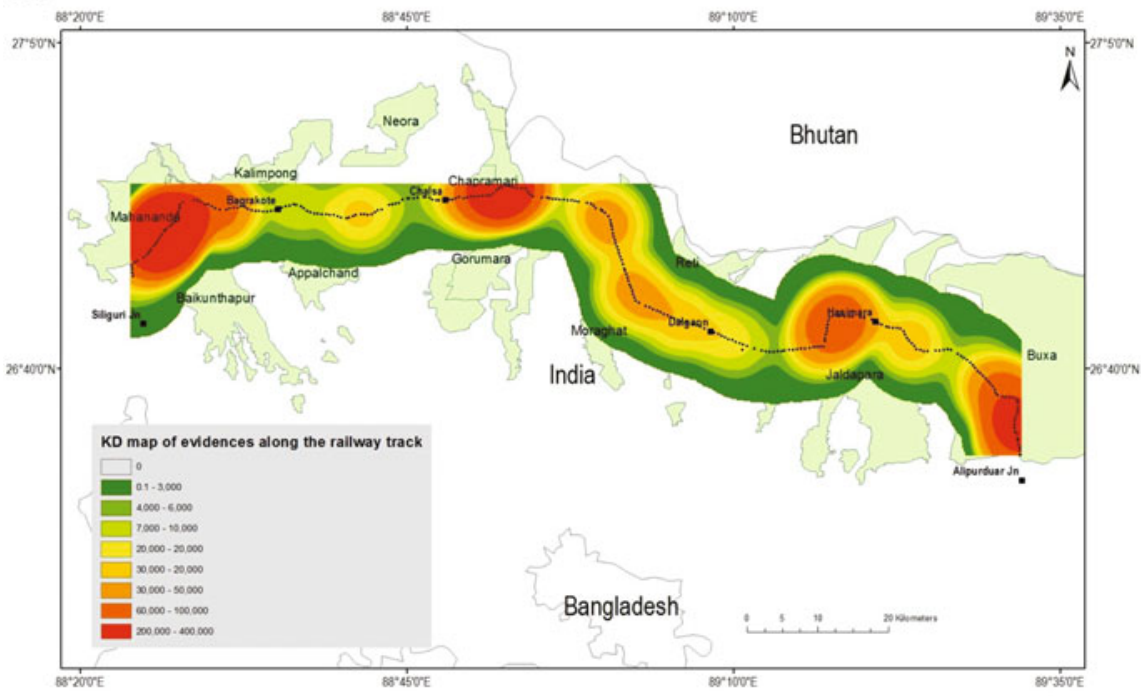

Fig. 10.6 Maps estimating the spatial variation in the risk of collision of elephants with trains along the railway track in northern West Bengal based on point densities (susceptibility map, upper panel a) and kernel densities (lower panel b)

increased from about $60 \mathrm{kph}(37 \mathrm{mph})$ to over $100 \mathrm{kph}(62 \mathrm{mph})$. A second possible reason for the increasing number of accidents was the increase in the elephant population of this region; the population more than doubled or even tripled here when 150 elephants were reported in 1980 from this region (Roy 2010). 
In terms of age and gender, we found that adults were killed more often than other age groups, but this was roughly proportional to their representation in the population. What is striking, however, is that the proportion of adult males killed was nearly three times higher than that expected from their representation in the population. The reasons for this are uncertain, but it is possible that adult males range over larger areas, raid crops in villages more frequently, and thus cross railways more often than females do (Sukumar 1989; Sukumar et al. 2003; Roy 2010; Williams et al. 2001). It is also noteworthy that juveniles were killed to a lesser extent than expected, implying that they are alert and protected within a family group, whereas calves were killed more often than expected from their percentage of the population, probably because of their inability to respond quickly to dangerous situations.

The concentration of accidents at night was probably a consequence of elephant movement patterns, rather than resulting from variation in the number of circulating trains. In fact, about $80 \%$ of accidents occurred between 18:00 and 6:00, although only $35 \%$ of trains operate at this time; this is probably because in daytime, elephants tend to rest in more dense forests, moving towards cultivated fields at night (Sukumar 2003) and eventually crossing railway lines. Other studies have reported similar patterns, showing a matching between animal daily activity patterns and collisions with trains. For instance, Ando (2003) found that $69 \%$ of the collisions of Sika deer Cervus nippon with trains in the eastern Hokkaido line, Japan, were recorded in the evening, which is the period when animals move between resting and feeding sites.

The seasonal distribution of collisions may also be a consequence, at least partly, of elephant movements from forests to agricultural areas, where they forage for crops. This is supported by the close matching between accident peaks and the harvest seasons of maize and paddy rice, as well as the observed spatial and temporal patterns of elephant raiding of crops in the region. Similar patterns have been observed elsewhere in India, with Singh et al. (2001) reporting that $78 \%$ of collisions with trains in the Rajaji National Park occurred in January-June and peaked in May, which matches the wheat and sugar cane cultivation/harvest season. Likewise, Sarma et al. (2006) in Assam found one peak in June-July during the active monsoon period, when elephants move away from floodplains to higher ground through which railway tracks run, and another in November that coincides with the paddy crop harvesting season. Studies on other herbivores, such as Sika deer (Ando 2003), moose (Alces alces, Andersen et al. 1991), and roe deer (Capreolus capreolus, Kusta et al. 2014), also suggested that collisions with trains peaked during the seasons when animals moved widely in search of food.

The spatial distribution of train-elephant collisions was uneven, with the occurrence of a few well-defined hotspots. Reasons for this are uncertain, but it may be the result of a number of factors, such as a variation in animal abundance, activity, and behaviour, habitat distribution, landscape topography, and rail design, as described for other species elsewhere (Gundersen and Andreassen 1998; Inbar and Mayer 1999; Haikonen and Summala 2001; Joyce and Mahoney 2001; Mysterud 2004; Roy 2010). In our case, accidents seemed concentrated in areas where the railway track crossed 
forested habitats heavily used by elephants, and in areas where elephants cross from forests to agricultural areas during their foraging movements. There is probably also a high risk of collisions in corridors that are used when animals move/migrate among forest patches, including the Reti Reserved Forest (RF)-Moraghat RF, Reti RF-Diana RF, Neora RF-Apalchand RF (Roy and Sukumar 2015).

It is not certain whether the observed mortality from collisions with trains has any significant impact on the local elephant population, but it is worth noting that train accidents from 2004 to 2013 were responsible for causing about $25 \%$ of the 224 elephant deaths recorded in northern West Bengal. This compares with a population size of 674 elephants estimated for northern West Bengal in 2015 (West Bengal Forest Department 2015), suggesting that there may indeed be some negative effects. As mentioned, the elephant population in this region has been increasing over the past three decades. Although northern West Bengal accounts for only $2.3 \%$ of the free-ranging elephant population in India, it is part of a much larger elephant population (about 2,700-3,000 animals) of the North Bank landscape (of the Brahmaputra River) that shares a contiguous habitat with Bhutan in the north and Assam in the east (Chowdhury and Menon 2006).

The impact of these accidents is very significant, Trains have to stop, elephants have to be removed, carriages may be damaged, etc. Due to these railways-elephant accidents revenue loss was estimated all over India Rs. 69,675.97 cores from freight and Rs. 28,645.52 cores (Nayak 2013).

\section{Management Implications}

Together with other studies (Singh et al. 2001; Sarma et al. 2006), our work clearly shows that elephant mortality due to collision with trains is a significant problem that urgently needs to be resolved. Addressing this issue requires that collision risks be duly considered in "environmental impact assessments," both when developing new railway projects, and when improving the operational characteristics of extant ones (e.g., changes from meter to broad gauge). These studies should assess the spatial and temporal patterns of elephant abundance, movements, and activity, thereby identifying areas where the risk of collision is high and new railway lines should not be laid. Where new lines are unavoidable, or where lines are already in operation, efforts should be targeted to mitigating impacts by implementing measures such as fencing, bridges, under- or overpasses, and local topography adjustments, among others. These processes should be conducted by technically qualified agencies in close collaboration with local and regional stakeholders, including government, NGOs, and the general public. It is also important that monitoring be put in place-in both the construction and exploration phases-aiming at the early detection of unanticipated impacts, and for assessing the efficiency of mitigation and compensation measures (Inell et al. 2003).

Along railway lines where collisions with elephants are frequent, such as in our study area, measures should be put in place to reduce the risks and thus avoid 
elephant mortality to the extent possible. Below are a number of recommendations that need to be considered in the Siliguri-Alipurduar line, and that may also be useful in similar areas elsewhere:

1. Reduce the speed of trains in the most vulnerable stretches of the track This suggestion has been repeated by several committees that have addressed trainelephant collisions in this region, but there have been genuine technical difficulties faced by the railway companies in implementing it due to operational constraints. With the current train operations along the Siliguri-Alipurduar line, it seems that reduced speed can only be implemented along a few stretches.

2. Limit the operation of trains during the night-time Since the frequency of accidents is much higher during the night than during the day, the curtailment of train movement along this track at night might be a possible way to reduce accidents. The acceptance of this suggestion would again depend on the operational needs of the railways.

3. Provision of overpasses and underpasses at vulnerable crossing points This would require an engineering survey along the entire stretch in order to determine the need, feasibility, and costs of any structure at locations where elephants are expected to cross more frequently. Considerable expenses would be incurred in undertaking such constructions. A pilot project on landscaping at some critical places such as Chalsa-Nagrakata, where the track is laid through a narrow passage in a hillock with steep excavation on either side, can be undertaken to assess its success or otherwise in reducing train elephant accidents. It is also important to consider whether elephants would use such engineered passages for crossing the railway track or would be suspicious of them and avoid them.

4. Patrolling along the track by forest/wildlife/railway staff This is already being practiced in northern West Bengal but can perhaps be strengthened during crop-raiding seasons, when the frequency of elephants crossing the tracks increases. The patrolling staff can then pass on the information to the railway signalmen on the presence of elephants. These measures are not without their problems, as patrolling at night inside dense forest is hazardous. The provision of more watch towers along the track in forest areas may be useful.

5. Implement garbage clearance and ensure better visibility along the track Elephants are attracted by food items, including packaged ones that passengers may throw out of trains. Creating awareness among passengers and employing staff to remove such garbage along the track would help reduce the possibility of elephants lingering along the railway track in search of food. Vegetation along the track has to be cleared on a regular basis to ensure the best possible visibility to train drivers who have to be sensitized to the risks of elephants crossing the tracks (such awareness is already being instituted among the drivers). There have been instances of elephants, usually solitary bulls, feeding on an attractive plant (such as banana) that grows close to a railway track, and being hit by a train. It is important to remove such elephant forage plants along the railway tracks. 


\section{Use of communications technology as an advance warning to train drivers} and signalling staff Electronic surveillance can be undertaken to assess its efficacy in detecting elephants close to the railway track. Various technologies have been suggested, including seismic sensors that measure ground vibrations to record elephant presence, infrared (thermal) sensors and cameras to provide images of elephants along railway tracks, infrared beams to detect the movement of an elephant, and even acoustic devices to scare elephants from tracks when trains are approaching. These require considerable R\&D for field situations, extensive field trials, and evaluation of cost-effectiveness before being deployed on a large scale. GPS collaring of representative animals in family herds and bulls would help in the fine-grained analysis of their movement pattern along the railway track, and help in planning mitigation measures.

7. Realignment of a portion of the track The existing track can be realigned so as to avoid passing through the Buxa Tiger Reserve West Division and the Jaldapara National Park, where a large number of accidents has taken place. The Southern line between New Jalpaiguri and New Alipurduar can be doubled to handle the increased traffic. There are four possibilities for realignment of the Northern line (Fig. 10.7).

(i) From the Dalgaon Railway station the track can be diverted and/or linked to the southern line, namely, Salbari-Falakata station between the New Jalpaiguri Junction- and the New Alipurduar Junction line so that some trains can be diverted before the Jaladapara-Buxa Reserve forest areas to avoid accidents.

(ii) From the Madarihat Station, the track can be diverted and/or linked to the southern line, namely, the Falakata station, along the New Jalpaiguri Junction-New Alipurduar Junction line so that some trains can be diverted before the Jaladapara-Buxa Reserve forest areas to avoid accidents.

(iii) From the Madarihat Station the track can be diverted and/or linked along the southwest periphery of the Jaldapara National Park (NP) and southern periphery of Jaldapara and Buxa Tiger Reserve (BTR) linked to Alipurduar Junction.

(iv) The fourth possibility is to realign the northern line from Hamiltanganj/ Kalchini to Damanpur by diverting the line along the south west border of the Buxa Tiger Reserve via Nimati and along south of highway NH31, which is linked to Damanpur, to avoid going through the Buxa Tiger Reserve.

Besides these technical recommendations, it should be kept in mind that limiting accidents to elephants from train collisions is extremely challenging, requiring the active participation of a number of stakeholders that include the Indian Railways, Ministry of Environment, Forest and Climate Change (Govt. of India), West Bengal Forest Department, NGOs, elephant biologists/conservationists, engineers and technologists, tea garden management, and the people living along the track. We suggest that various solutions be implemented at an experimental level, and then monitored over a reasonable time frame for testing their efficacy. The most cost-effective solutions should then be selected and implemented on a larger scale, thereby reducing collision risks and ultimately contributing to the conservation of elephants in India and elsewhere in Asia 


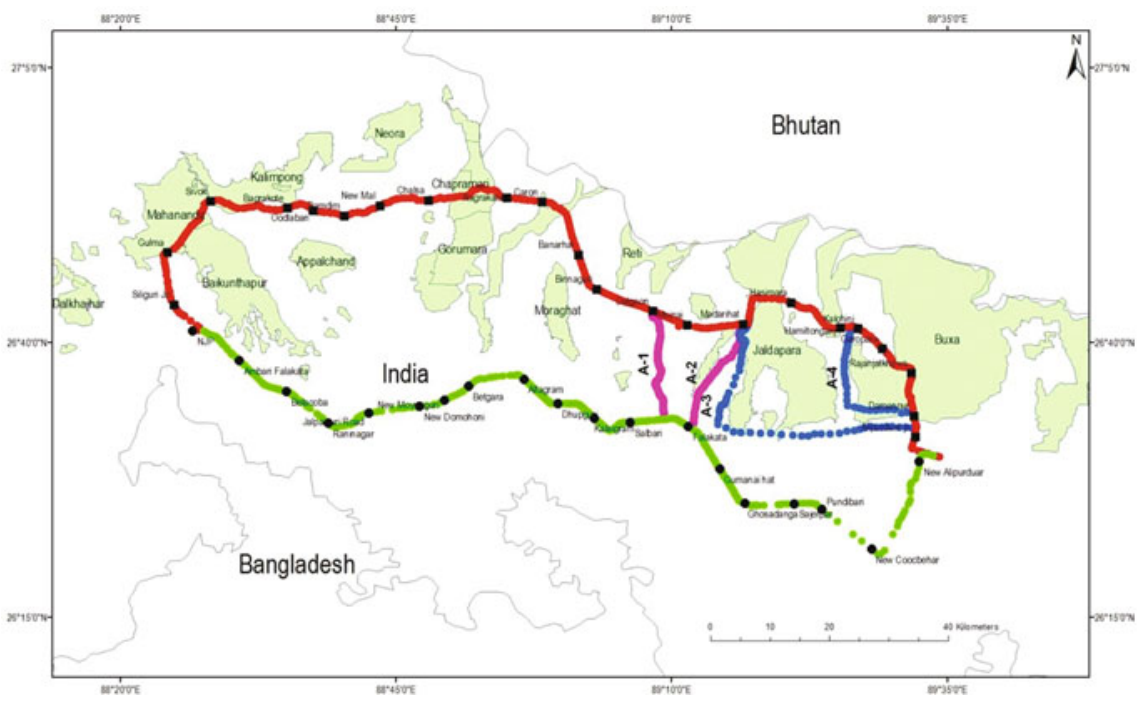

Fig. 10.7 Suggestions for realignment of the existing railway track from the Siliguri Junction to the Alipurduar Junction to reduce the risk of train-elephant collisions in northern West Bengal. \#Red line Northern sector railway track (Siliguri Junction-Alipurduar Junction). \#Green line Southern sector railway track (New Jalpaiguri-New Alipurduar Junction) that does not pass through any forest. \#Pink lines Possible realignment of track (Dalgaon- Falakata (A-1), MadarihatFalakata (A-2)). \#Blue dotted lines Possible realignment of proposed track (Madarihat-Alipurduar Junction $(A-3)$ and Hamlitonganj-Damanpur $(A-4)$ )

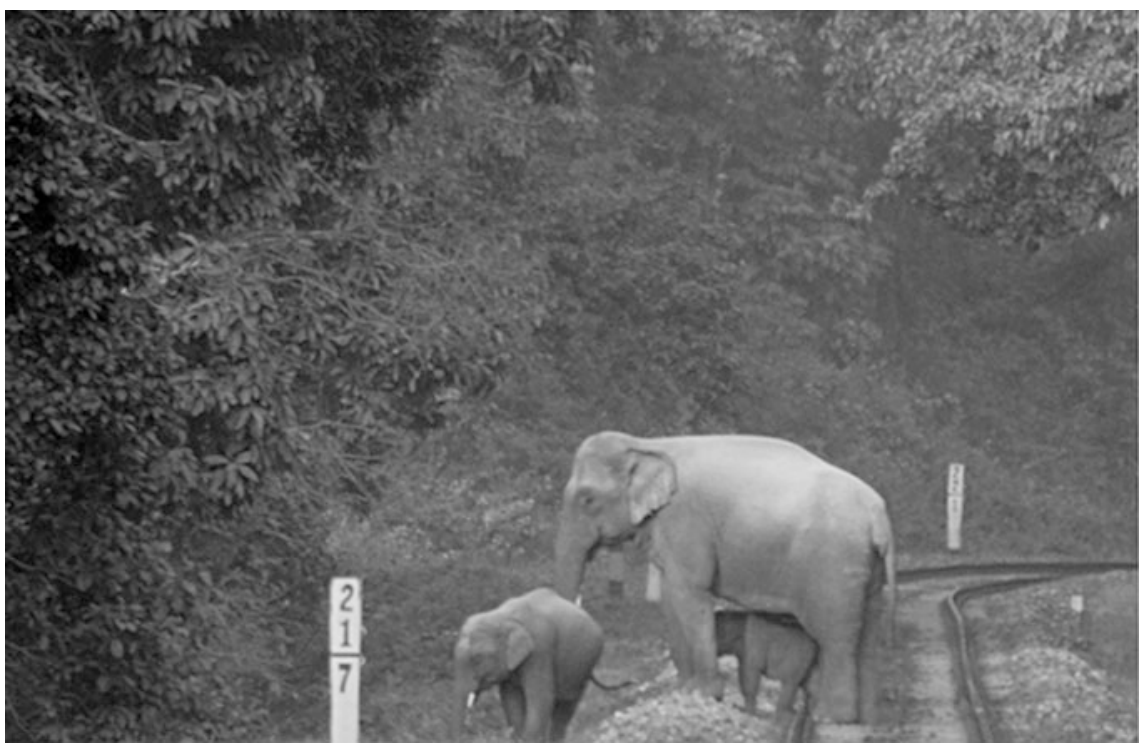

Photo credit @Debopratim Saha 
Acknowledgements We thank the International Elephant Foundation, the primary agency that funded this project; the Asian Nature Conservation Foundation for the work place and administration of the project; the Centre for Ecological Sciences, Indian Institute of Science, for office space, Internet and report writing; the West Bengal Forest Department for permissions and help in the field to carry out the study; the Indian Railways (North Frontier Railway) for permissions to survey along the track; the Dooars Branch of the Indian Tea Association for permissions to survey elephant paths within their tea gardens; and the Environmental System Research Institute for providing online software as well as Arc GIS 10.3.1. We also thank Mr. Santosh Chhetri, Mr. Sapwan Chhetri, Mr. Sushil Manger, Mr. Rabin Chhetri, Mr Ratua Oran, Mr. Rohit Munda and Mr. Bikash Kairala for their help in the field, often under difficult conditions.

\section{References}

Andersen, R., Wiseth, B., Pedersen, P. H., \& Jaren, V. (1991). Moose-train collisions: Effects of environmental conditions. Alces, 27, 79-84.

Ando, C. (2003). The relationship between deer-train casualties and daily activity of the sika deer, Cervus nippon. Mammal Study, 28, 135-143.

Caughley, G., \& Sinclair, A. R. E. (1994). Wildlife Ecology and Management. Cambridge, MA: Blackwell Science.

Child, K. N., Barry, S. P., \& Aitken, D. A. (1991). Moose mortality on highways and railways in British Columbia. Alces, 27, 41-49.

Chowdhury, A., \& Menon, V. (2006). Conservation of Asian elephant in north-east India. Gajah, $25,47-60$.

Clarke, G. B., White, P. C. L., \& Harris, S. (1998). Effects of roads on badger Meles meles populations in south-west England. Biological Conservation, 86, 117-124.

Conover, M. R., Pitt, W. C., Kessler, K. K., Dubow, T. J., \& Sanborn, W. A. (1995). Review of human injuries, illnesses, and economic losses caused by wildlife in the United States. Wildlife Bulletin, 23, 407-414.

Das, K. (2013). Man Elephant Conflict in Northern Bengal. Unpublished report to TERI University. Retrieved on November 05, 2016, from http://www.teriuniversity.ac.in/mct/pdf/ assignment/Kalyan-Das.pdf

Dasgupta, S., \& Ghosh, A. K. (2015). Elephant-railway conflict in a biodiversity hotspot: Determinants and perceptions of the conflict in Northern West Bengal, India. Human Dimensions of Wildlife, 20, 81-94.

Dorans, R. A. P., Kindel, A., Bager, A., \& Freitas, S. R. (2012). Avaliação da mortalidade de vertebrados em rodovias no Brasil. In A. BAGER (ed.), Ecologia de estradas: tendências e pesquisas. Lavras: UFLA, pp. 139-152.

ESRI. (2014). ArcGIS Desktop: Release 10.3.1. Redlands, CA: Environmental Systems Research Institute.

Fahrig, L., Pedlar, J. H., Pope, S. E., Taylor, P. D., \& Wegner, J. F. (1995). Effect of road traffic on amphibian density. Biological Conservation, 73, 177-182.

Forman, R. T. T., \& Deblinger, R. D. (2000). The ecological road-effect zone of a Massachusetts (USA) suburban highway. Conservation Biology, 14, 36-46.

Formann, R. T. T., Sperling, D., Bissonette, J. A., Clevenger, A. P., Cutshall, C. D., Dale, V. H., et al. (2003) Road Ecology: Science and Solutions (481 p). Washington: Island Press.

Fahrig, L., France, R., Goldman, C. R., Heanue, K., \& Jone, I. A. (2003) Road ecology: Science and solutions $(481 \mathrm{p})$. Washington: Island Press.

Ghosh, L. (2001). Tracking death. India today. Retrieved November 5, 2016 from, http:// indiatoday.intoday.in/story/railway-expansion-project-increases-threat-to-wildlife-in-bengalsanctuaries/1/232130.html) 
Government of West Bengal, Forest Department (GoWB). (1957). Sixth working plan of the reserved forests of Jalpaiguri Division (1957-58 to 1966-67), Vol. 1, prepared by the Divisional Forest Officer, Jalpaiguri Division.

Government of West Bengal. (2012). State forest reports: 2006-2012. Kolkata: Government of West Bengal, Directorate of Forests, Office of the Principal Chief Conservator of Forests.

Government of West Bengal. (2013). State forest reports: 2013. Kolkata, India: Government of West Bengal, Directorate of Forests, Office of the Principal Chief Conservator of Forests.

Government of West Bengal. (2015). Synchronized population estimation of the Asian elephant in forest divisions of Northern West Bengal-2014. Jalpaiguri, West Bengal: West Bengal, Directorate of Forests, Office of Conservator of Forests.

Government of India. (2015). Indian railways lifeline of the nation (A White Paper) February 2015, Ministry of Railways New Delhi.

Gundersen, H., \& Andreassen, H. P. (1998). The risk of moose Alces alces collision: A predictive logistic model for moose train accidents. Wildlife Biology, 4, 103-110.

Haikonen, H., \& Summala, H. (2001). Deer-vehicle clashes: Extensive peak at 1 hour after sunset. American Journal of Preventive Medicine, 21, 209-213.

https://en.wikipedia.org/wiki/Track_gauge_in_India

http://indiatoday.intoday.in/story/railway-expansion-project-increases-threat-to-wildlife-in-bengalsanctuaries/1/232130.html

Inbar, M., \& Mayer, R. T. M. (1999). Spatio-temporal trends in armadillo diurnal activity and road-kills in central Florida. Wildlife Society Bulletin, 27, 865-872.

Indian Railways. (2014). Statistical summary —Indian railways. Retrieved November 05, 2016, from http://indianrailways.gov.in/railwayboard/uploads/directorate/stat_econ/IRSP_201314/ pdf/Statistical_Summary/Summary\%20Sheet_Eng.pdf

Inell, B., Bekker, G. J., Cuperus, R., Dufek, J., Fry, G., Hicks, C., et al. (Eds.). (2003). Wildlife and traffic: A European handbook for identifying conflicts and designing solutions. Brussels: European Co-operation in the Field of Scientific and Technical Research.

Jha, N., Sarma, K., \& Bhattacharya, P. (2014). Assessment of elephant (Elephas maximus) mortality along Palakkad-Coimbatore railway stretch of Kerala and Tamil Nadu using Geospatial Technology. Journal of Biodiversity Management \& Forestry, 3, 1-7.

Joyce, T. L., \& Mahoney, S. P. (2001). Spatial and temporal distributions of moose-vehicle collisions in Newfoundland. Wildlife Society Bulletin, 29, 281-291.

Kusta, T., Hola, M., Keken, Z., Jezek, M., Zika, T., \& Hart, V. (2014). Deer on the railway line: Spatiotemporal trends in mortality patterns of roe deer. Turkish Journal of Zoology, 38, 479-485.

Lalo, J. (1987). The problem of road kill. American Forests, 50, 50-52.

Modafferi, R. D. (1991). Train moose kill in Alaska: Characteristics and relationships with snowpack depth and moose distribution in Lower Susitna Valley. Alces, 27, 193-207.

Mysterud, A. (2004). Temporal variation in the number of car-killed red deer Cervus elaphus in Norway. Wildlife Biology, 10, 203-210.

Ministry of Environment and Forests (MOEF). (2010). Gajah: Securing the future for elephants in India. New Delhi, India

Nayak, S. (2013). A petition under article 32 of the Constitution of India in the nature of public Interest litigation challenging the inaction of ministry of Environment \& Forest, Indian railways and many State Governments and under their failure to protect wealth like the elephants, In the Supreme Court of India, New Delhi.

Newmark, W. (1987). A land-bridge island perspective on mammalian extinctions in western American parks. Nature, 325, 430-432.

Palai, N. C., Bhakta, P. R., \& Kar, C. S. (2013). Death of elephants due to railway accidents in Odisha, India. Gajah, 38, 39-41.

Raman, T. S. R. (2011). Framing ecologically sound policy on linear intrusions affecting wildlife habitats (background paper for the National Board of Wildlife). Mysore: Nature Conservation Foundation. 
Ray, S. (2002). Transformations on the Bengal frontier: Jalpaiguri 1765-1948. Curzon, NY: Routledge.

Roy, M., Baskaran, N., \& Sukumar, R. (2009). The death of jumbos on railway lines in northern West Bengal. Gajah, 31, 36-39.

Roy, M. (2010). Habitat use and foraging ecology of the Asian Elephant (Elephas maximus) in Buxa Tiger Reserve and adjoining areas of northern West Bengal. Ph.D. thesis, Vidyasagar University, West Bengal, India.

Roy, M., \& Sukumar, R. (2015). Elephant corridors in northern West Bengal. Gajah, 43, 26-35.

Roy, M., \& Sukumar, R. (2016). Survey of elephant movement paths/corridors across rail tracks in northern West Bengal. Final Report to International Elephant Foundation, March 2016.

Seiler, A., \& Helldin, J. O. (2015). Greener transport infrastructure-IENE 2014 international conference. In A. Seiler \& J. O. Helldin (Eds.), Proceedings of IENE 2014 International Conference on Ecology and Transportation, Vol 11, pp. 5-12. Malmö, Sweden. Nature Conservation. doi:10.3897/natureconservation.11.5458

Sarma, U. K., Easa, P. S., \& Menon, V. (2006). Deadly lines: A scientific approach to understanding and mitigating elephant mortality due to train hits in Assam (Occasional Report no. 24). New Delhi: Wildlife Trust of India.

Silverman, B. W. (1986). Density estimation for statistics and data analysis. New York: Chapman and Hall.

Singh, A. K., Kumar, A., Mookerjee, A., \& Menon, V. (2001). Jumbo express: A scientific approach to understanding and mitigating elephant mortality due to train accidents in Rajaji National Park (Occasional Report no. 3). New Delhi: Wildlife Trust of India.

Soule, M. E., \& Wilcox, B. A. (Eds.). (1980). Conservation biology: An evolutionary-ecological perspective. Sunderland, MA: Sinauer.

Sukumar, R. (2011). The story of Asia's elephants. Mumbai: Marg Foundation.

Sukumar, R. (1989). The Asian elephant: Ecology and management. Cambridge: Cambridge University Press.

Sukumar, R. (2003). The living elephants: Evolutionary ecology, behavior and conservation. New York: Oxford University Press.

Sukumar, R., Baskaran, N., Dharmarajan, G., Roy, M., Suresh, H.S., \& Narendran, K. (2003). Study of Elephants in the Buxa Tiger Reserve and adjoining areas of northern West Bengal and preparation of Conservation action plan. Final Report submitted to West Bengal Forest Department. Centre for Ecological Sciences, Indian Institute of Science, Bangalore, India.

Trombulak, S. C., \& Frissell, C. A. (2000). Review of ecological effects of roads on terrestrial and aquatic communities. Conservation Biology, 14, 18-30.

Van der Ree, R., Jaeger, J. A. G., Van der Grift, E. A., \& Clevenger, A. P. (2011). Effects of roads and traffic on wildlife populations and landscape function: Road ecology is moving towards larger scales. Ecology and Society, 16, 48.

Wilcove, D. S., Rothstrin, D., Dubow, J., Philips, A., \& Locos, E. (1998). Quantifying threats to imperiled species in the United States. BioScience, 48, 607-615.

Williams, A. C., Johnsingh, A. J. T., \& Krausman, P. R. (2001). Elephant-human conflicts in Rajaji National Park, north-western India. Wildlife Society Bulletin, 29, 1097-1104. 
Open Access This chapter is licensed under the terms of the Creative Commons Attribution 4.0 International License (http://creativecommons.org/licenses/by/4.0/), which permits use, sharing, adaptation, distribution and reproduction in any medium or format, as long as you give appropriate credit to the original author(s) and the source, provide a link to the Creative Commons license and indicate if changes were made.

The images or other third party material in this chapter are included in the chapter's Creative Commons license, unless indicated otherwise in a credit line to the material. If material is not included in the chapter's Creative Commons license and your intended use is not permitted by statutory regulation or exceeds the permitted use, you will need to obtain permission directly from the copyright holder. 